tioners would meet, would at least be interesting and might well be beneficial to both.

For secondary schools, the centres would afford admirable opportunities for individual or group work in many subjects, including natural history, biology, geology, geography, history, art and allied studies. Many school syllabuses in biology-largely dictated by external examinations - are too academic to appeal to the average boy and girl, and are, therefore, not of the real educational value that they should be. Children are interested in studying living plants and animals in their natural environment, and it is coming to be realized among educationists that this aspect of the subject needs to be greatly encouraged ; but unfortunately, fow teachers-including university graduates in the biological scienees-have the requisite first-hand knowledge and experience of field-work to teach natural history with competence and enthusiasm. In biology (a subject which purports to be the science of living things), it is far easier to teach and examine classes of pupils by anatomizing dead specimens in the laboratory than by observing living organisms in the field, and this may account for the comparative neglect of the study of animals and plants in their natural habitats.

The evacuation scheme, whereby the schools were dispersed from the cities of Britain into the countryside during the War, has shown only too clearly that for many teachers the countryside is a closed book; comparatively few seem to have been able to make use of the excellent opportunities presented to them for first-hand observation and teaching in the field, even when there was no external examination syllabus to tie them down to an unadventurous and monotonous urban class-room routine. Moreover, in schools permanently situated in the country, it is the exception rather than the rule to do any serious work in the field in school hours, in studies (other than gardening) which specially lend themselves to observational work and the testing and illustrating of teaching and text-book authority at first hand. Admittedly, this work requires detailed knowledge and a carefully planned technique, which are at present outside the range of experience of many teachers in the schools, not having been demanded in their university studies or dealt with in their courses of professional training. The centres will be equipped and organized to enable this special knowledge of field-work to be acquired by teachers and pupils in the various subjects; also teachers will be able to learn the technique of handling classes in the field, which undoubtedly requires special training, experience and facilities, if the work is to be efficient and time and energy conserved. In course of time, perhaps, when the centres have become widely established, new influences will be brought to bear on school and university teaching and examining, and then the Council for the Promotion of Field Studies will be "filling the very important gap which exists in our system of education both at the school and university level". It is hoped that the centres will be widely used by teachers and pupils in the schools, and that they will enjoy working out the fresh approach to culture that field-studies will bring them, with new kinds of technique, in places of great natural beauty that should rejoice the hearts of artists and craftsmen, as well as scientific men, geographers and historians.

Finally, the Council for the Promotion of Field Studies is a scientific society, and therefore it is important that the spirit of research should not be confined to field and laboratory, but should be applied to the planning, organization and equipment of the centres, and, indeod, to the general administra. tion of the Council's activities as a whole. What these activities will be in their completeness it is not yet possible to forecast; but from the widespread and eminent support that the Council has already received, it would seem that we are on the fringe of great possibilities of service to those who wish to make a first-hand study of the many branches of knowledge that have their source and inspiration in the field.

\section{THE SEVERN BARRAGE SCHEME}

COAL supplies in Great Britain having become 1 deficient in quantity and quality, public atten. tion has been forcibly directed towards alternative sources of power and energy. The most novel and also the largest single source which has attracted public interest is the Severn Barrage. A scheme formulated by Mr. A. G. Vaughan-Le日, Sir William Halcrow and Mr. S. B. Donkin, published by the Ministry of Fuel and Power*, gives a broad outline of a method of utilizing tidal power in the Severn Estuary, provides an estimate of the amount of power and energy which would be made available, and the cost thereof.

The principle of the scheme is simple. A dam across the Severn enables water to be impounded on rising tides. This water flows through turbines on the succeeding falling tides. Its potential energy is converted to kinetic energy by the turbines and then to electrical energy by alternators directly coupled to these turbines.

The proposed dam is located at the English Stones, some two and a half miles downstream from the mouth of the River Wye, a rough locating point on the north bank of the Severn being the village of Snabrook. It is about two miles long, and comprisés sections for inlet sluices, navigation locks and turbines. Thirty-two turbines, in two equal groups, would drive thirty-two alternators, each rated $25 \mathrm{MW}$. at 0.9 power factor. These would be capable of providing a maximum power output of $800 \mathrm{MW}$. At spring tide, when the power available is greatest, the total output from the alternators would rise to a maximum of $800 \mathrm{MW}$. in two and a half hours, remain at this value for four hours, and then fall to zero in a further period of about one hour. There would thus be two periods of about seven hours during each twenty-four, in which the plant would be able to generate power and energy. The maximum power and the hour at which it is available changes day by day in accordance with the state of the tide. These daily and seasonal changes of the power and energy output are to be balanced by suitable operation of the barrage power in conjunction with the electricity grid system of Britain.

The gross energy available at the barrage would be 2,365 million $\mathrm{kWh}$. per annum. If the water flow through the turbines were continuous, the energy available per annum would be 7,008 million $\mathrm{kWh}$. The ratio $\frac{2,365}{7,008}$, that is, $0 \cdot 47$, is important when

* Ministry of Fuel and Power. Report of the Severn Barrage Scheme. By A. G. Vaughan-Lee, Sir William Halcrow and S. B. Donkin. Pp
32. (London: H.M. Stationery Office, 1945.) 28. 6d. net. 
considering the relative merits of the barrage scheme and of other sources of energy, such as interconnected thermal power stations, where the maximum output can be maintained continuously if some 15 per cent of spare plant is provided. About one million tons of coal per annum would be saved by using the Severn power. To maintain constant electrical frequency and output, the turbines are to be of the Kaplan type, with variable-pitch propeller-type runners.

The magnitude of the project can be gauged by considering the quantity of material to be used and the labour to be expended.

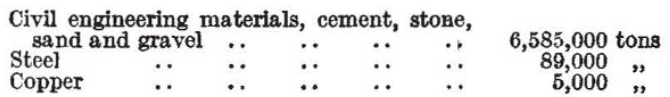

The labour required for manufacturing plant and constructing the barrage would be 86,840 man-years. The report suggests that the constructional time should be eight years, with an average of 10,355 persons in service over that period. The estimated cost of the barrage (1944 basis) is $£ 40 \cdot 22$ million. This is $£ 50$ per $\mathrm{kW}$. of plant installed. Thermal power stations cost about $£ 30$ per kW., but they have a power-delivering ability of about 85 per cent as compared with 47 per cent for tidal stations. They can also be sited closer to power-consuming centres, and cen be operated to suit the load requirements.

Ordinary hydro-electric stations, such as are scheduled for construction by the North of Scotland Hydro-electric Board, will cost about $£ 53$ per $\mathrm{kW}$. Their power availability factor is not precisely known, but should be of the order of 80 per cent, and is certainly far higher than that of a tidal scheme.

Viewed from the conventional economic point of view, the prospects of the Severn Barrage scheme appear to be bleak. It is, nevertheless, possible or even probable that it will become expedient to construct the Severn scheme in the fairly near future. This renders it particularly interesting to consider its prospects from a practical engineering aspect.

No justifiable doubt exists as to the ability of British engineers to construct the barrage, civil engineering works and electrical equipment. Laymen are liable to be apprehensive about possibilities of disaster, or at least crushing expenditure due to erosion downstream, and silting upstream from the barrage. This aspect has, however, been fully clarified by an admirable series of experiments made by Prof. A. H. Gibson on a scale model of the relevant part of the Severn estuary with and without the barrage. A detailed survey of the estuary made by the Admiralty in 1849 had established the contours of the river bed at that time. Prof. Gibson was able to show that he could reproduce on his model the changes which were caused in the undammed Severn by scouring and silting. Similar experiments on the model provided with a barrage enabled Prof. Gibson to indicate, it is believed accurately, what will take place in the Severn over a period of sixty years after the Severn scheme is put into service.

Prof. Gibson's remarkable investigation, in the best tradition of Osborne Reynolds, has made it possible to predict accurately what the total costs of electricity generated at the Severn Barrage will be over a long term of years. The figure for the energy cost given in the report is $0 \cdot 199 \mathrm{~d}$. per $\mathrm{kWh}$. at the barrage.

There is an unfortunate tendency on the part of the public to hamper development of schemes of the Severn Barrage class because they are deemed to be 'huge'; nevertheless the fact remains that its cost is only the equivalent of some three days of the British expenditure during the War.

In this connexion, it may be useful to direct attention to a water-power scheme at Catrine, Ayrshire, which was put into service in 1837 , and which continues to function to this day, as perfectly as it did initially. The Catrine scheme uses the power of the River Ayr. Two overshot water wheels, each $50 \mathrm{ft}$. in diameter, develop 800 h.p. This power is transmitted to a factory by a shaft $200 \mathrm{ft}$. long. The hydro-power fluctuations are evened out by a 200 h.p. beam, which started work in 1847 and which is still in action.

Although the Severn Barrage is about a thousand times as large as the Catrine scheme, considered as a risk to the community it is trifling compared with that faced and overcome more than a hundred years ago by forgotten Ayrshiremen. Those now responsible for electrical development in Great Britain are not lacking in enterprise, and will doubtless set the Severn to work at its appointed time.

\section{SYMBIOTIC NITROGEN FIXATION}

\author{
By PROF. ARTTURI I. VIRTANEN \\ Biochemical Institute, Helsinki
}

INCE 1940 I have not had the opportunity of
reporting to English readers the results of our investigations on symbiotic nitrogen fixation. As an opportunity now offers itself, I will briefly record in the following the chief points of our research during the War.

Oxaloacetic acid, which according to my conception has a central position in the formation of aspartic acid, has been determined in several leguminous plants at different stages of growth and under different lighting conditions, employing a method previously described ${ }^{1}$. The oxaloacetic acid content of the plant is highest at noon and in the afternoon, lowest after the night. If the plants are kept for two days in the dark, the oxaloacetic acid disappears. The pea contains before flowering usually about $50 \gamma$ oxaloacetic acid per 1 gm., determined at noon, and red elover about $100 \gamma$. At the end of flowering and when growth ceases oxaloacetic acid is no longer detected in plants ${ }^{2}$.

We have been able to isolate bacterial strains of Rh. leguminosarum which causes nodulation on peas but do not fix nitrogen at all (in ten experiments, inoculated pea plants contained on the average $7.5 \mathrm{mgm}$. N. per plant, uninoculated control plants $7.3 \mathrm{mgm}$.). By using our sterile culture system, we have been able to show that this is a constant property of this bacterial strain. Although the bacteria were allowed to pass through five plant passages they did not become active nitrogen fixers. The experiments with ineffective and very effective bacterial strains have without exception led to the conclusion that all the reports in the literature on the change of an ineffective strain to an effective one and vice versa through successive plant passages are erroneous and due to the fact that the experiments have been carried out in open pots. In such conditions there is always a great danger of contamination by foreign strains. Only in a sterile culture system can reliable results be obtained. 